INVESTIGACIÓN/RESEARCH

\title{
EL PROFESIONAL DE LOS MEDIOS EN EL CINE DE LOS ÚLTIMOS AÑOS
}

Paula Requeijo Rey ${ }^{1}$ : Universidad Complutense de Madrid. España. p.requeijo@ccinf.ucm.es

\section{RESUMEN}

Entre 1930 y 1999 se estrenaron en España 77 películas en las que el periodista juega un papel central. En el mismo período, el número de títulos asciende a 703 si incluimos aquéllos en los que simplemente aparece un profesional de los medios. Hay especialistas que hablan de un género o subgénero: el cine de periodistas. Desde 1975, encontramos a distintos autores que analizan la imagen del reportero en las películas (Maxwell Taylor, Alex Barris, Juan Carlos Laviana, Richard Ness, Larry Langman, Loren Ghiglione o Joe Saltzman). Lo habitual es que se centren en títulos emblemáticos desde los orígenes del cine hasta finales de los años 90. En el presente estudio, nos ocupamos de la representación del periodista en algunos de los largometrajes de la última década. Utilizamos el análisis de contenido y combinamos los modelos de la Teoría Profesional, la clasificación elaborada por el periodista Juan Carlos Laviana y la del profesor Joe Saltzman. El objetivo fundamental es determinar si hay algunas imágenes que predominan, cuáles son sus características, si junto a los MCM aparecen otros poderes y cómo se relaciona el reportero con ellos. En los cinco filmes analizados hay tres imágenes principales: la del periodista grato, la del comprometido y la del mánager. Aparecen representados el poder ejecutivo, el económico, el judicial y el de las fuerzas y cuerpos de seguridad. En unos casos se muestra lo positivo de la colaboración entre poderes y en otros la relación es negativa.

PALABRAS CLAVE: Imagen - Periodista - Cine - Modelos de análisis.

\footnotetext{
${ }^{1}$ Autor correspondiente

Paula Requeijo Rey: Personal Investigador Contratado. Departamento de Periodismo III, Facultad de Ciencias de la Información, Universidad Complutense de Madrid.

Correo: p.requeijo@ccinf.ucm.es
} 


\title{
THE MEDIA PROFESSIONAL IN THE CINEMA OF RECENT YEARS
}

\begin{abstract}
Between 1930 and 1999, 77 films in which the journalist plays a central role were released in Spain. In the same period, the number of these titles, if we include those in which a media professional just appears, reaches to 703. Some authors speak of a genre or subgenre called cinema of journalists (or journalists' cinema). Since 1975, we find several authors who analyzed the image of the reporter in films (Maxwell Taylor, Alex Barris, Juan Carlos Laviana, Richard Ness, Larry Langman, Loren Ghiglione or Joe Saltzman). These authors usually focus on flagship titles from the origins of cinema until the late 90 's. In our study, we discuss the representation of journalists in some films of the last decade. We use content analysis and we combine the models of Professional Theory, the classification drawn by the journalist Juan Carlos Laviana and the one of Professor Joe Saltzman. The main objective is to determine if there are any dominant images, their characteristics, the question of other powers that appear alongside MCM and how the journalist relates with them. There are three main images in the five films analyzed: the pleasant journalist, the committed one and the manager. The executive, the economic, the judiciary and the security and police forces are also represented. In some cases the positive collaboration between authorities is shown and in other ones the displayed relationship in the film is negative.
\end{abstract}

KEY WORDS: Image - Journalist - Cinema - Analysis models.

\section{INTRODUCCIÓN}

El periodista ha protagonizado numerosos filmes desde los comienzos del cine. Horsewhipping the Editor, hecha ya en el año 1900, se considera como la primera película sobre periodismo. Nos muestra a un hombre iracundo que ataca al director de un diario. En otro de los primeros filmes, del año 1903, Delivering Newspapers, nos encontramos a un grupo de chicos que reparten periódicos (Saltzman, 2002a, p. 3).

Antes del cine, la literatura se interesa por el reportero y durante los siglos XVIII y XIX ayuda a consolidar su imagen. De hecho, las primeras películas se inspiran en las novelas del siglo XIX. Parece que la labor de búsqueda, creación y difusión de la noticia, que en muchas ocasiones se tiñe de suspense y drama, resulta atractiva al público. Los reporteros "cuentan historias, hostigan a un acusado o preguntan sobre asuntos de la trama que interesan (...)" (Valbuena, 1997, p. 124).

Otras veces, simplemente, se recurre a elementos propios del mundo de la comunicación como las "portadas, los flases, los anuncios por palabras, los ejemplares saliendo de las rotativas (...) los locutores (y) los aparatos de radio o televisión" para desarrollar una historia (Laviana, 1996, p. 10). 
Los largometrajes dedicados al periodismo son numerosos, por lo que podemos hablar de un género o subgénero. Olga Osorio ha elaborado una lista sobre las películas producidas entre 1930 y 1999 en las que el periodista juega un papel central. Ha tenido en cuenta dos criterios fundamentales: a) que se hayan estrenado en España ${ }^{2}$ y b) que giren en torno a la figura del profesional y no a la de los medios de comunicación en general. El número de títulos asciende a 77 (Osorio, 2009, pp. 449-451).

La cantidad aumenta considerablemente (879) si tenemos en cuenta los filmes en los que simplemente aparece algún periodista. Aquí, Osorio también contabiliza los títulos realizados entre 1914 y 1929 (cinco) y entre 2000 y 2009 (171). Si nos atenemos exclusivamente a los que se producen entre 1930 y 1999, como en la clasificación anterior, el número desciende a 703.

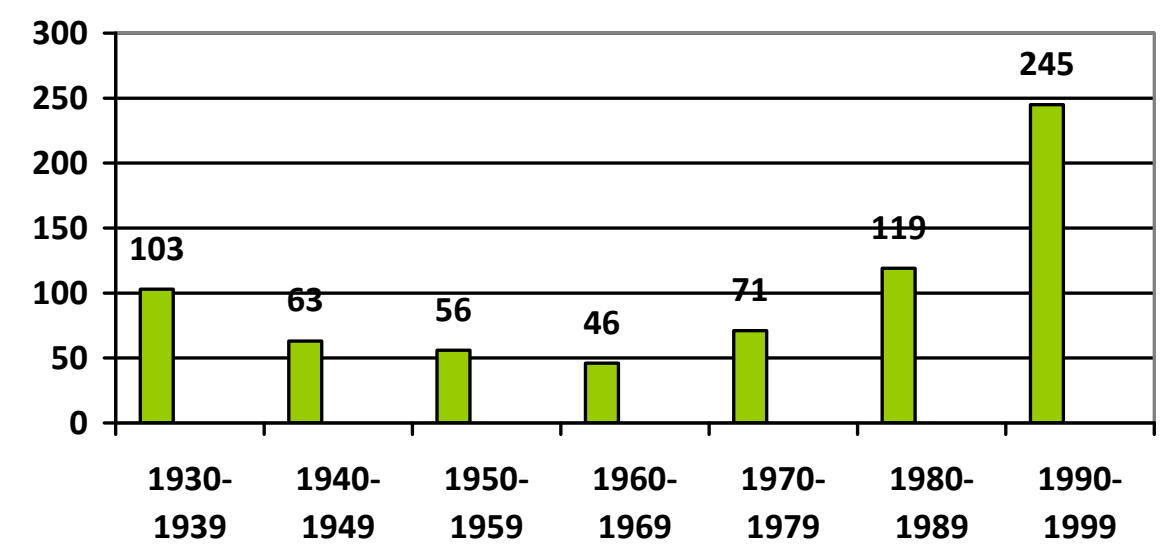

Gráfico 1: Películas en las que aparece algún periodista por décadas (1930-1999). Fuente: Elaboración propia a partir de los datos incluidos en Osorio, 2009, pp. 452-470.

Hay varios autores, especialmente anglosajones, que han analizado la relación entre el cine y el periodismo. El primero que se interesa por este asunto es Maxwell Taylor Courson que lo elige como tema para su tesis doctoral "The newspaper movies: an analysis of the rise and decline of the news gatherer as a hero in american motion pictures". Abarca los filmes producidos entre 1900 y 1975 y la presenta en 1976 en la Universidad de Hawaii (Osorio, 2009, pp. 19). Ese mismo año, el canadiense Alex Barris edita Stop the Presses! The Newspaperman in American Films en el que establece seis categorías de análisis. Su clasificación ha tenido y todavía tiene mucha influencia. Otros estudiosos del tema son Howard Good, periodista y profesor en la State University de Nueva York, Richard Ness, Larry Langman, Loren Ghiglione y Mathew Ehrlich.

Es importante destacar el proyecto "Image of the Journalist in the Popular Culture" (La Imagen del Periodista en la Cultura Popular). Es una iniciativa del Centro Norman Lear, Escuela de Comunicación y Periodismo Annenberg, de la Universidad del Sur de

\footnotetext{
2 Para elaborar esta filmografía ha tenido en cuenta las que se citan en las principales bibliografías sobre este tema y la Base de Datos del Ministerio de Cultura. Además de los filmes estrenados en España, también ha incluido otros que se han hecho populares gracias al formato VHS o DVD.
} 
California (USC). Lo dirige Joseph Saltzman y, además del cine, se centra en otros campos. Cuenta con una importante base de datos y una revista académica (más adelante ofrecemos información detallada acerca del proyecto).

El interés por la imagen que las películas ofrecen de los periodistas está sobradamente justificado. El papel de los medios de comunicación, entre ellos el cine, no sólo como mediadores entre el ser humano y la realidad, sino como creadores de esa realidad es clave. A través de ellos nos formamos una visión del mundo y su influencia en nuestras percepciones, ideas y opiniones es, por tanto, indiscutible. Las películas influyen en el concepto que la opinión pública tiene sobre los profesionales de los medios. El propósito de este estudio es determinar que representaciones ofrecen algunos de los filmes producidos en los últimos años. ¿Qué imágenes construyen? ¿Hay algunas que predominen? ¿Cuáles son sus características?¿Cómo es la relación del periodista con el medio para el que trabaja? ¿Se muestra la relación con otros poderes? ¿Con cuáles?

\section{METODOLOGÍA}

El método de investigación adoptado combina el análisis de contenido y el enfoque cualitativo, que permite una aproximación completa y objetiva al tema de estudio. Nos hemos servido de varios tipos de clasificaciones. El primer tipo (en adelante le llamaremos Tipo 1) se ocupa de estudiar la imagen del periodista en general. Tiene una larga trayectoria y su validez ha sido probada en numerosas ocasiones. El Tipo 2 se ocupa exclusivamente del periodista cinematográfico.

El estudio de los profesionales de la información comienza en Estados Unidos, en los años 30, gracias a Harold Lasswell. “Animó a un célebre periodista, Leo Rosten, a que estudiase a fondo a los periodistas que él conocía y con los que había trabajado durante años. De ahí salió la obra The Washington Correspondents, publicada en 1937" (Valbuena, 1997, p. 114).

Los modelos de Tipo 1 surgen en la década de los 50. Se desarrollan a partir de las autobiografías y obras que los periodistas han escrito, y de las conclusiones de los investigadores. Éstos, identifican la imagen que los reporteros tienen de sí mismos por medio de encuestas. Valbuena los recoge en lo que denomina la Teoría Profesional (Valbuena, 1997, p. 81-138).

Los modelos Tipo 2 que empleamos se basan en la obra de Barris. Son el de Laviana (1996) y el de Saltzman (2002a). Ambos incluyen 13 categorías.

La mayor parte de los estudios que van más allá de un mero ensayo, se centran en títulos o directores emblemáticos. Abarcan desde los inicios del cine hasta finales de 
los años 90. De ahí que la muestra que hemos seleccionado pertenezca a la última década. ${ }^{3}$

\begin{tabular}{|l|c|c|c|c|}
\hline \multicolumn{1}{|c|}{ Película } & Director & Año & País & $\begin{array}{c}\text { No espectadores en } \\
\text { cine España }\end{array}$ \\
\hline El dilema & Michael Mann & 1999 & EEUU & 441.489 \\
\hline $\begin{array}{l}\text { Verónica } \\
\text { Guerin }\end{array}$ & Joel Schumacher & 2003 & $\begin{array}{c}\text { Cop. EEUU, } \\
\text { Irlanda e Inglaterra }\end{array}$ & 132.237 \\
\hline $\begin{array}{l}\text { El precio de la } \\
\text { verdad }\end{array}$ & Billy Ray & 2003 & EEUU y Canadá & Dato no disponible \\
\hline $\begin{array}{l}\text { Buenas Noches } \\
\text { y Buena Suerte }\end{array}$ & George Clooney & 2005 & EEUU & 638.583 \\
\hline $\begin{array}{l}\text { El desafio: Frost } \\
\text { contra Nixon }\end{array}$ & Ron Howard & 2008 & EEUU & 61.908 \\
\hline
\end{tabular}

Tabla 1: Películas seleccionadas, director, año, país y número de espectadores en cine en España. Fuente: elaboración propia.

Hemos seleccionado estos largometrajes y no otros porque son conocidos en España. Además del número de espectadores que los han visto en el cine no debemos olvidar la importancia que el DVD y las descargas de Internet han tenido en los últimos años.

Como se puede observar en la tabla, en todos está presente Estados Unidos. Hemos elegido películas norteamericanas porque ésta es la nacionalidad de la mayoría de títulos en los que el periodismo es el tema central. Según el estudio de Osorio (2009) que ya hemos mencionado, “de las 77 películas estrenadas hasta el año 2000" (entre 1930 y 1999) en España "seis son de origen español (6,49\%), frente a 58 títulos norteamericanos $(75,32 \%)^{\prime \prime}$. España está en segundo lugar empatada con Italia (6,49\%), aunque a mucha distancia de Estados Unidos. Esto tiene sentido porque hablamos de películas estrenadas en nuestro país. Así “es lógico que el cine español tenga una representación mayor que el del resto de Europa” (Laviana, 1996, p. 65).

\subsection{Modelos empleados}

\subsubsection{Modelos de tipo 1}

Periodista grato y punitivo. Desarrollado por De Sola Pool y Shulman (De Sola Pool e Irwin Shulman, 1964, pp. 141-158) tras entrevistar a una treintena de periodistas. Distingue entre el grato, que busca agradar a la audiencia para que ésta lo tenga en buena consideración y el punitivo, que concibe su trabajo como un instrumento para luchar contra las injusticias.

\footnotetext{
${ }^{3}$ Hablamos de la última década porque El Dilema se estrena en España el 11 de febrero de 2000. En Estados Unidos el cinco de noviembre de 1999.

4 Datos obtenidos en la base de películas calificadas del Ministerio de Cultura de España: $\underline{\text { http:// } w \text { ww.mcu.es/bbddpeliculas/cargarFiltro.do?layout=bbddpeliculas\&cache=init\&language=es }}$
} 
- Periodista de revelación o exclusiva y mánager periodístico. Deriva de los estudios de Tunstall (1970) y distingue entre la figura heroica, que sale en busca de la noticia, y la que dirige y organiza.

- Periodista participante y neutral. Los conceptos se recogen en el artículo The Professional Values of American Newsman ("Los valores profesionales del informador americano") que Johnstone publicó en el Public Opinion Quarterly junto a Salawski y Browman en 1972. En el primer caso "la noticia es vista emergiendo naturalmente de los sucesos y ocurrencias del mundo real, y al periodista le basta ser espectador del proceso social en marcha y transmitir fielmente una comunicación precisa sobre el mismo. El periodismo responsable puede conseguirse mediante la objetividad, precisión en los hechos y verificación de la información (...) La relación del periodista con la información es así de despego y neutralidad" (Johnstone y otros, en Valbuena, 1997, p. 117).

El segundo se identifica con la idea de la prensa como perro guardián. El periodista debe implicarse e ir más allá, investigar para crear la noticia.

- Periodista profesor y abogado. Janowitz (1960) establece similitudes entre el periodista y otros profesionales como los militares. Esta clasificación se corresponde con la anterior. El profesor busca la objetividad y le interesa la labor educativa de los medios. El abogado mantiene una actitud participativa y representa a los más débiles, que no tienen visibilidad.

- Periodista sabueso y misionero. Hasta ahora hemos visto modelos que surgen del trabajo de los profesionales norteamericanos. La investigadora alemana Renate Köcher (1986, pp. 43-64) estudia a los periodistas ingleses y alemanes. Diferencia entre los sabuesos, que recurren a medios poco ortodoxos (presionar a las fuentes, mentir) aunque entienden su labor como transmisora y educativa frente a los misioneros, que buscan influir, ser líderes de opinión.

- Valbuena propone un modelo que tenga en cuenta los estilos de comportamiento, que se basan en los tipos psicológicos de Carl Gustav Jung.

El reflexivo está orientado hacia sí mismo y le interesan las ideas. Necesita un tiempo para procesarlas. El intuitivo está orientado al futuro y es creativo. "Tiene un fino sentido para lo latente preñado de futuro (...) Como anda siempre a la busca de nuevas posibilidades, en circunstancias estables corre peligro de asfixia. Capta, ciertamente, nuevos objetos y orientaciones nuevas con gran intensidad (...)"(Jung, 1971, p. 138).

En cambio, el perceptivo "es, en todos los aspectos, el reverso del intuitivo. Se basa, por decirlo así, exclusivamente en el elemento de la percepción sensible (...) Se atiene, pues, íntegramente al estímulo real (Jung, 1971, p. 197). Está orientado al pasado, le interesan las personas porque "su yo reside, en cierto modo, en su afección, es decir, en su relación" (Jung, 1971, p. 26), y es empático. Por último, el dinámico, busca la acción y es capaz de tomar decisiones de forma rápida.

Con los estilos de comportamiento se introduce un importante componente psicológico a la hora de analizar qué mueve a los periodistas. 


\subsubsection{Modelos de tipo 2}

Alex Barris es uno de los primeros en estudiar las imágenes del periodista en el cine. Distingue entre el fustigador del crimen, el que se dedica a los escándalos, el cruzado, el corresponsal y el paño de lágrimas (hace referencia a la mujer que parece una periodista de raza pero no duda en dejarlo todo con el objetivo de formar una familia. Encontraremos de nuevo esta categoría dentro del esquema de Saltzman).

El periodista Juan Carlos Laviana propone en su ensayo Los chicos de la prensa (1996) un modelo basado fundamentalmente en el puesto que ocupa el profesional de la información. Aunque él mismo explica que su libro no es "una recopilación académica" nos parece interesante por la riqueza de imágenes que ofrece. Se estructuran en 13 categorías:

- El magnate de los medios (su máximo exponente es Charles Foster Kane, protagonista de Ciudadano Kane, 1941).

- El director (Ed Hutchinson, de El cuarto poder, 1952).

- El redactor jefe (James Ganon, de Enséñame a querer, 1958).

- El periodista político (Bob Woodward y Carl Bernstein, de Todos los hombres del presidente, 1976).

- El enviado especial.

- El reportero amarillo.

- El periodista comprometido (Domingo "Pajarito", de La verdad sobre el caso Savolta, 1975).

- El crítico y columnista.

- El reportero de sucesos.

- El periodista de sociedad.

- El cronista deportivo.

- El fotógrafo.

- Los otros chicos de la prensa (se trata de "una legión de abejas obreras, de ratas de redacción, que trabajan sin cesar para que esas estrellas puedan triunfar" (Laviana, 1996, p. 341).

El profesor y periodista Joe Saltzman es el director del proyecto IJPC (Image of the Journalist in the Popular Culture, La Imagen del Periodista en la Cultura Popular), dentro de la USC (Universidad del Sur de California). El IJPC empezó a investigar en 2003 qué representaciones ofrecen del periodista el cine, los medios de comunicación (televisión y radio), los anuncios, la animación, los cómics, el arte, la literatura, la música, los videojuegos y otros productos de la cultura popular. El objetivo es analizar el impacto de estas imágenes en la percepción que el público tiene de los profesionales de la información para entender cómo se siente respecto al periodismo y sus actores.

Los responsables del IJPC intentan que el conocimiento que generan llegue a la mayor parte de gente posible. Han creado una base de datos en Internet abierta al público con más de 75.000 elementos. La mayor parte son norteamericanos pero también cuentan con material de otras partes del mundo. Esta base de datos puede ser una herramienta muy útil a la hora de inspirar y facilitar investigaciones sobre el tema que 
nos ocupa.

El proyecto no se olvida de la dimensión educativa. Ofrece toda una serie de materiales para organizar desde clases hasta una asignatura completa en la que estudiar la representación del periodista a través del uso de varias clasificaciones y el visionado de distintas películas.

El esquema de Saltzman coincide con algunas de las categorías planteadas primero por Alex Barris y después por Laviana. Las citamos brevemente: reporteros anónimos, columnistas y críticos, cachorros, directores o responsables, periodistas estropeados, periodistas de investigación, familias memorables de la redacción, fotoperiodistas, editores y propietarios de medios, periodistas de la vida real, paños de lágrimas, periodistas deportivos y corresponsales de guerra. Las ha aplicado al cine de Frank Capra (Saltzman, 2002b).

\section{ANÁLISIS Y DISCUSIÓN}

\subsection{El dilema}

El Dilema (The insider, 1999) es una película dirigida por Michael Mann y basada en un hecho real: el despido del jefe de investigación y desarrollo de la tabacalera Brown y Williamson, Jeffrey Wigand, por no aceptar que manipulasen la nicotina en la elaboración de cigarrillos. La empresa era consciente de que al añadir a la nicotina sustancias químicas, el pulmón la absorbe con más rapidez y afecta al cerebro y al sistema nervioso. Sin embargo, les convenía hacerlo así para crear dependencia en los fumadores y que mantuvieran o aumentaran su nivel de consumo de cigarrillos.

El productor del espacio informativo con más prestigio y más audiencia de Estados Unidos, Lowell Bergmam, trata de convencer a Wigand de que revele esa información en su programa. El problema es que Brown y Williamson le ha obligado a firmar un contrato de confidencialidad con el que pueden demandarle y llevarle a prisión si habla. Para asegurarse de que permanecerá callado, le amenazan con hacer daño a su familia o incluso con matarlos. Esto último es un recurso dramático del filme ya que en la vida real, como se explica en los créditos finales, nunca se identificó a la fuente de las amenazas de muerte y nadie ha sido acusado ni procesado.

Lowell es un periodista de investigación. Para Saltzman esta figura representa al "único héroe legitimo de los filmes periodísticos". Se caracterizan por "trabajar incansablemente para ayudar al público" y no dudan en "arriesgar su vida" y dejar a un lado su "beneficio personal o seguridad" por "una historia que saque a la luz el crimen o la corrupción" (Saltzman, 2002a, p. 7). En los primeros minutos ya queda clara su valentía. Viaja hasta Líbano y allí, consiente que unos extraños le lleven en coche con los ojos vendados para encontrarse con uno de los líderes de Hezbolá. Su actitud, pausada y tranquila, contrasta con la de su compañero, Norman. Por otro lado, sabe convencer a otros. Domina la motivación positiva directa, una de las claves de la publicidad: convertir los atributos en beneficios. 
Líder Hezbolá.- Explíqueme por qué he de acceder a una entrevista con un medio de comunicación prosionista americano.

Lowell.- Porque creo que Hezbolá ahora está tratando de convertirse en un partido político así que le importa lo que se opina de ustedes en América. Y en América en este momento Hezbolá no tiene rostro. Por eso.

Líder.- Podría demostrar su objetividad periodística si me enseña antes las preguntas. Entonces decido si concedo la entrevista.

Lowell.- No, no hacemos eso. Ya ha visto 60 minutos y a Mike Wallace así que conoce nuestra reputación de integridad y objetividad y sabe que somos el informativo de mayor audiencia y con más credibilidad de toda América. ¿Entonces el señor Wallace coge un avión o no?

Líder.- Dígale que le recibiré pasado mañana.

Al volver de Líbano, recibe una caja con unos informes. No sabe de qué se tratan. Intuye que pueden estar relacionados con el tabaco pero no es capaz de entender lo que allí se recoge y llama a un compañero. "¿Tú o alguien de Sanidad podríais decirme quién puede traducirme esto al cristiano?". Esta acción es propia de un periodista divulgador, que busca ofrecer un marco a su audiencia y para ello pide que le simplifiquen la jerga propia de otro campo. Su compañero le remite a Jeffrey Wigand, pero al telefonearle su mujer no le permite hablar con él. Vuelve a llamar y deja un mensaje con su número. Después decide enviarle un fax. Ante la negativa de Jeffrey a ayudarle, busca rápidamente en la guía de teléfonos la dirección de un hotel de Louisville, en donde vive Wigand, y le deja otro mensaje:

Lowell.- Si siente curiosidad por verme estaré en el hotel Seelbach de Lousiville leyendo el New York Times mañana a las cinco en punto.

$\mathrm{Su}$ actitud, según los estilos de comportamiento basados en los tipos psicológicos de Jung es propia de una persona intuitiva. A la hora de alcanzar un objetivo, si falla una de las ideas que pone en práctica, en seguida se le ocurre otra. No importa que no le coja el teléfono, le deja un mensaje. Da igual que no quiera hablar, le envía un fax.

Además, toma decisiones de forma rápida y organiza a otros trabajadores para alcanzar un objetivo. Su estilo secundario es dinámico.

Sabe tratar a su fuente, Wigand. Es consciente de sus necesidades. Se da cuenta de que tiene frente a él a un hombre reflexivo, al que le cuesta expresarse y tomar decisiones y perceptivo, que se preocupa casi más por las personas que le rodean (su mujer y sus hijas) que por sí mismo. Por eso no le presiona y escucha sus preocupaciones. También le aconseja y le hace ver cuáles son las dos posibilidades que tiene.

Lowell.- Entonces, tiene usted un conflicto Jeff porque ahora su situación es ésta: si posee información interna vital, que el propio pueblo americano por su bien debería saber y se siente obligado a revelar y violar su acuerdo a la vez, es una opción. Y si lo que quiere es respetar el acuerdo, entonces es simple: hágalo, no haga nada, no diga nada. Sólo hay alguien que pueda tomar esa decisión y es usted, nadie más. 
Un matón persigue a Wigand en un campo de golf. Empieza a sospechar que alguien vigila su casa, recibe una bala en un sobre por correo y un e-mail con una amenaza de muerte. Cena con Lowell en un restaurante y éste le explica por qué debe contar lo que sabe:

Wigand.- Solo soy mercancía para usted, ¿verdad? Otra más. Algo que meter entre anuncios. Lowell.- Para una cadena tal vez. Todos lo somos. Para mí no es una mercancía sino alguien importante. Si lo hace público y 30 millones de personas escuchan su historia nada, créame, nada volverá a ser lo mismo. ¿No me cree?

Wigand.- No.

Lowell.- Debería. Porque cuando lo haga se dictará una sentencia en el tribunal de la opinión pública amigo mío y eso es mucho poder.

Lowell está seguro de la importancia de su trabajo. Es un periodista misionero que busca influir en el público para poner en marcha, como él mismo dice, al "tribunal de la opinión pública". Finalmente, Wigand graba el programa pero la dirección de la CBS no permite su emisión. Se oponen, pero no de forma directa, sino poniendo objeciones: "nos pueden demandar", "es necesario asegurarse", "quizás nuestro testigo no es veraz", etc ... Lowell es un periodista comprometido que cree en lo que hace y no acepta la censura que le imponen sus jefes. Esta conversación refleja el choque que se produce entre el periodista de revelación, que sale en busca de la noticia y se debe a su audiencia y el manager, que tiene intereses de tipo empresarial.

Nos encontramos aquí con el primero de los cinco filtros de la Teoría de la Propaganda de Herman y Chomsky: los medios se mueven por criterios de rentabilidad. “(...) Las empresas dominantes en los medios de comunicación son grandes negocios, están controladas por personas muy poderosas o por directivos sometidos a severas limitaciones por parte de los propietarios y otras fuerzas orientadas hacia los beneficios de mercado, y están estrechamente unidas y tienen importantes intereses comunes con otras grandes empresas, con los bancos y con el gobierno. Es el primero de los poderosos filtros que afectará decisivamente a la selección de noticias" (Herman y Chomsky, 2001, p. 42).

La compañía Eléctrica Westinghouse está a punto de comprar la CBS y, lejos de pensar en el interés de la audiencia, sólo le interesa obtener beneficios. No pueden arriesgarse a que Brown y Williamson les demande. Es una de las consecuencias de la concentración. Los medios forman parte ahora de conglomerados que poco o nada tienen que ver con el periodismo y "la pluralidad, la información y la cultura" pasan a ser "valores secundarios" (Segovia, 2004, p. 57). Esta idea se refleja en lo que Lowell le dice al productor ejecutivo de la CBS:

Lowell: Tú oyes razonable e injerencia torticera. Yo oigo: posible pleito de Brown y Williamson comprometiendo la venta de CBS a Westinghouse. Corta el reportaje. Deja a Wigand solo. Obedece órdenes y a la mierda. Eso es lo que oigo... Y Jeffrey Wigand que está en la cuerda floja, ¿va a ir a la televisión a contar la verdad? Sí. ¿Es un caso que interesa? Sí. ¿Vamos a emitirlo? Claro que no. ¿Por qué? ¿Porque no cuenta la verdad? No. Porque va a contar la 
verdad y por eso no vamos a emitirlo. Y cuanta más verdad cuente, peor resultará... Vamos, ¿qué eres tú? ¿Un hombre de negocios o un informador?

Mike Wallace se muestra como un periodista punitivo, que ve en su trabajo un mecanismo para hacer frente a las injusticias. Sin embargo hay un momento en que parece ceder a las presiones.

Mike Wallace.- No pienso pasar el final de mis días paseando en la jungla de la radio pública nacional.

Emite una versión del programa en la que no desvela la identidad de su fuente ni la de la tabacalera a la que se refiere, pero, finalmente, muestra la original.

Acusan a Wigand de ser un mentiroso y el Wall Street Journal y el Post van a publicar un artículo. Es una estrategia de Brown y Williamson para desprestigiarle y que nadie dé crédito a la información que revele. Lowell decide filtrar la información de todo lo que pasó en la CBS al New York Times y así restituir la credibilidad de su fuente y sacar a la luz los excesos de los poderosos. La noticia se publica en primera página y la CBS acabará por emitir la entrevista de Wallace con Wigand en 60 minutos.

Wallace muestra a Lowell su deseo de seguir haciendo el programa juntos, como los últimos 14 años, pero él no acepta. Está decepcionado con el periodismo porque, como le explica a su mujer, "la prensa es libre sólo para sus dueños". Por tanto, esto imposibilita la misión que para un periodista de investigación como él tienen los medios: revelar a la audiencia verdades que permanecen ocultas. Sin embargo, gracias a su tenacidad, la industria del tabaco tuvo que hacer frente a las demandas presentadas primero en Mississipi, y después en otros 49 estados más por 246 billones de dólares. El periodismo actuó como perro guardián aunque tuviera que enfrentarse contra los titulares de los medios y algunos de sus profesionales.

\subsection{Verónica Guerin}

Joel Schumacker es el director de la película Verónica Guerin (2003) que se centra en los dos últimos años de la vida de la periodista del mismo nombre. Tiene una estructura circular: en el prólogo y el epílogo se narra el asesinato de la reportera, que se produjo el 26 de junio de 1996. Un par de años antes, Verónica, que trabajaba para el diario The Sunday Independent, comenzó a investigar quiénes eran los jefes de las redes del narcotráfico de su país. El tráfico de drogas era entonces uno de los mayores problemas de Irlanda, como se recoge al principio del filme: "Elevó la delincuencia a los niveles más altos jamás conocidos... 15.000 personas se inyectaban heroína cada día, algunos tenían 14 años".

Los primeros veinte minutos de la película son los que peor retratan el caso de Guerin debido fundamentalmente a tres aspectos: 
1) Falta de verosimilitud basada en las pobres actuaciones de los intérpretes secundarios en la dimensión verbal y la no verbal, la forma de desarrollar los diálogos y la caracterización de varios personajes.

2) Uso forzado de la música. Una canción celta acompaña la mayor parte de las escenas y, en lugar de subrayar determinados aspectos de las mismas, les da un tinte melodramático, exageradamente sentimental.

3) Durante estos primeros minutos, los comportamientos de esta periodista de investigación de la vida real son más bien los de una paparazzi o una "reportera anónima" (Saltzman, 2002ª , p. 6). "El verdadero periodismo de investigación es aquel en el que el periodista, a través de intuición, su trabajo, su esfuerzo y sus propias fuentes, descubre algo que el público no conoce y que las personas afectadas desean mantener en el más estricto secreto" (Caminos, 1997).

Verónica no se dirige a las fuentes adecuadas. Se presenta en la casa de uno de los narcotraficantes, Martin Cahill. En la puerta, con un bebé en brazos, está su mujer.

Verónica.- ¿Es usted la Señora Cahill? ¿Francis Cahill? (La Señora Cahill se mete dentro de la casa y sale al jardín). Bien (Verónica la encuentra alli de nuevo). ¿Es usted Francis Cahill?

Señora Cahill.- Sí.

Verónica.- Soy Verónica, una amiga de John Traynor.

Señora Cahill.- Sé quién es.

Verónica.- ¿Está su marido en casa?. Quiero pedirle un favor.

Señora Cahill.- Martin Cahill no hace favores a los periodistas. Así que, lárguese.

Verónica.- Se rumorea que vende droga. ¿Algún comentario? Clavó a un "reventa" en el suelo. ¿Fue por una cuestión de droga? Sólo quiero un comentario extraoficial. Me iré en cuanto..

No entiendo por qué entra aquí el Señor Cahill, que antes no ha aparecido.

Señor Cahill. ¿Podría hacerme un favor? Necesito los nombres de los chavales a los que les vende la droga. Y yo le haré un favor. No escribiré lo que dicen sobre usted. Ya sabe. Que tiene hijos con sus cuñadas. Aquí tiene mi número. Llámeme. Hasta luego.

Es habitual que las personas resentidas estén dispuestas a hablar pero, ¿por qué va a hacerlo el jefe de una red de narcotráfico con un próspero negocio? Es obvio que no está interesado en revelar ningún tipo de información que le perjudique a él mismo. Además, ¿cómo va a conseguir persuadirle invadiendo su privacidad y gritándole preguntas?

Lo más ridículo e inverosímil es la última cuestión que le plantea: ingenuamente, pretende que Martin Cahill le diga el nombre de los menores a los que usa para la venta de droga. El quid pro quo que le sigue no se queda atrás: no revelar que tiene hijos con sus cuñadas a cambio de los nombres. Está claro que no se ha puesto en la mente del otro: es probable que a un narcotraficante, asesino y torturador, no le preocupe demasiado que los medios afirmen que tiene hijos con sus cuñadas.

Si comparamos su actitud con la del periodista de El Dilema, vemos que actúa de forma opuesta. Lowell no va en ningún momento a encontrarse con el presidente de Brown y Williamson. Su fuente es Wigand, un hombre al que han despedido de esa 
empresa y que siente la necesidad de hablar. Lowell no lo hostiga a preguntas sino que se toma su tiempo para conocerlo y tratar de ver qué necesita.

No queremos decir que sólo exista una forma de proceder en el periodismo de investigación, pero sí que hay que saber elegir a las fuentes y negociar con ellas. La propia Verónica demuestra más adelante la importancia de colaborar con otros poderes y de consultar informes.

La película no consigue retratar de forma creíble a esta periodista de la vida real, pero mejora tras este dudoso comienzo. Poco a poco, Verónica adquiere una actitud propia de una periodista de investigación. Cahill es asesinado y el IRA se responsabiliza de su muerte. Ella utiliza su intuición al darse cuenta de que es falso. Como la propia familia del muerto afirma, los autores son otros mafiosos. Comienza a mostrarse como una persona intuitiva que apenas descansa para alcanzar su objetivo (dinámica).

Comienza a visitar a Chris, un policía que tiene información sobre Cahill y otras personas relacionadas con las drogas. Gracias a él descubre al auténtico jefe de la red de narcotráfico, que permanece en la sombra, John Gilligan.

En un principio, el diputado por Dublín, Tony Gregory, se muestra contrario a las actuaciones de Verónica:

Gregory.- Ninguna banda está involucrada en el asesinato de Cahill (...) No ha habido una masacre gracias a que la familia Cahill no se traga este cuento. Esta mujer es una incendiaria, trata los rumores como hechos.

Sin embargo consigue su apoyo, lo que le permite consultar los registros de propiedades de las empresas de Gillighan y saber quiénes son los accionistas que las conforman. Tiene acceso hasta a su declaración de la renta. Es un ejemplo de los beneficios que derivan de la colaboración entre poderes.

Verónica se muestra como punitiva y misionera. Ve en el periodismo un instrumento con el que luchar contra las injusticias y busca influir, cambiar las circunstancias.

Verónica.- (...) ¿Crees que me gusta hacerlo? No me gusta hacerlo. Tengo que hacerlo.

Marido.- Eres periodista, escribes. Deja que la policía se encargue.

Verónica.- ¡Venga ya! La policía no puede hacer nada. Se librarán. Ha habido 14 tiroteos en 14 meses.

Marido.- Lo sé, tú has sido uno.

Verónica.- Sé quiénes son... No se saldrán con la suya.

Verónica.- Encarcelan a los periodistas por hacer su trabajo. Sugerí aumentar las penas para delitos relacionados con las drogas (...) Los inspectores de hacienda. Se les paga sólo por recoger los ingresos declarados y no preocuparse si provienen de la droga. La policía puede incautarse el dinero de las drogas pero no quedárselo. 
Es abogada y adversaria. Defiende a los que no tienen visibilidad sacando a la luz los desmanes de los poderosos.

Verónica.- ¡Qué panorama! Las calles llenas de jeringuillas por el suelo donde jugaban los niños. Tenías que haber visto a esos cabrones, allí de pie, junto a sus Mercedes. ¿Cuántas dosis de cinco libras tienes que vender para poder comprar un Mercedes? Echa las cuentas. ¿Cuántos chavales serían? Nadie escribe sobre eso. ¿A quién le interesa? No importa. Alguien tiene que perseguir a esos cerdos. Se están forrando. Yo debería escribir sobre esto. No serían chorradas.

Entrevistador.- ¿Por qué se arriesga?

Verónica.- Quiero llamar la atención sobre una cultura que existe en nuestra sociedad y de la que nadie sabe nada.

Si dejamos a un lado el comienzo, Verónica es una periodista de investigación que no duda en "arriesgar su vida" por "una historia que saque a la luz el crimen o la corrupción". Aún después de recibir amenazas, un disparo en la pierna, una paliza y de que su propia familia y sus jefes le pidan que deje la investigación sobre el narcotráfico, sigue adelante. No es extraño que estos reporteros acaben por encontrarse con la muerte, que llega de manos de un "gángster", uno de los asesinos u hombres corruptos implicados en su historia o "un policía corrupto" (Saltzman, 2002a, p 7). Verónica es asesinada por Brian Meehan que sigue órdenes de John Gilligan. Su muerte hizo despertar a la población, que comenzó a manifestarse contra el narcotráfico. La presión social provocó importantes cambios en las leyes.

\subsection{El precio de la verdad}

Este filme de Billy Ray (Shattered Glass, 2004) reconstruye una historia real: la del joven Stephen Glass (24 años) que trabajó como reportero de la prestigiosa revista The New Republic. Glass era uno de los periodistas más prometedores de Washington, y tanto su publicación como otras (Rolling Stone o Harper's) admiraban la originalidad de sus artículos y su capacidad para conseguir testimonios de las fuentes más variopintas. Sin embargo, lo que parece un gran olfato para la búsqueda de temas y protagonistas sorprendentes, se revela como un talento innato para el desarrollo de historias de ficción: sus reportajes son inventados.

Al comienzo del filme lo vemos en una de las clases de su antiguo instituto. Una de las profesoras que tuvo lo ha invitado para que dé una charla a los alumnos sobre cómo trabaja un buen periodista. Él, visiblemente motivado al tener un público que le escuche, explica sus impresiones sobre la profesión:

Stephen Glass.- Algunos periodistas creen que el contenido politico es lo que hace memorable un artículo. Yo creo que son las personas que descubres. Sus rarezas, sus defectos, aquello que los hace curiosos o más humanos. El periodismo es el arte de captar el comportamiento.

Stephen Glass.- Tienes que saber para quién escribes. Y tienes que saber qué se te da mejor. Yo tomo nota de lo que hace la gente. Averiguo qué la mueve, qué la asusta. Y sobre eso escribo. De este modo son las personas las que cuentan la historia. 
A través de estas afirmaciones es fácil entender que Glass es una persona intuitiva. A primera vista, puede parecer perceptivo, porque le interesan los otros. Sin embargo, no pretende contar historias sobre ellos sino manipularlos. Él no se fija en el comportamiento o las necesidades de sus fuentes, que no existen porque sus artículos son inventados. Estudia a sus propios compañeros, a sus jefes y a los directores de otras revistas. El objetivo es gustarles, agradarles, para que le tengan en buena consideración. Una vez que sabe a quién tiene enfrente, trata de complacerle diciéndole lo que quiere oír o haciendo algo por él.

Maneja una destreza comunicativa que es clave a la hora de obtener información sobre el otro: la escucha activa. Presta atención al receptor y, a través de lo que dice y cómo lo dice, extrae sus pensamientos y sentimientos. Así, sabe cómo ha de tratar a los demás y cómo hacerles sentir que son importantes.

El periodismo es para él un ejercicio de vanidad:

Stephen Glass.- Está mal pagado, le dedicas una cantidad de horas tremenda, pero lo que escribes lo leen personas importantes: presidentes, legisladores... Tu trabajo quizás influya en la política del país. Eso, eso es un increíble privilegio y una gran responsabilidad. Sólo queréis ver vuestro nombre publicado, ¿no? Eso me es familiar.

Hay que tener en cuenta que miente al hablar de la responsabilidad. Sólo le interesa estar en la plantilla de un medio de prestigio dirigido a las élites para sentirse poderoso De ahí que su charla a los alumnos tampoco sea real. Es algo que imagina para sentirse admirado e importante. En su recreación de la escena, hay tres detalles que subrayan su necesidad de reconocimiento: un marco colgado en la pared de la clase con algunos fragmentos y titulares de sus mejores trabajos, una profesora que se coloca a su lado sonriente subrayando sus cualidades y una chica que flirtea con él.

Es un periodista grato porque con sus textos inventados busca gustar a la audiencia para que al igual que sus compañeros le tengan en buena consideración. A pesar del riguroso sistema de comprobación de artículos que sigue The New Republic (dos procesos de revisión que incluyen a tres correctores diferentes y abogados), es un redactor de la revista Forbes - en su modalidad on-line- el que descubre el fraude. Se lo comunica al jefe de Glass, Chuck Lane.

Glass hará todo lo posible para hacerle creer que en Forbes están equivocados: abre una página web a nombre de la empresa, proporciona teléfonos con contestadores automáticos, imprime la tarjeta de visita de un agente y hasta hace que su hermano, que está en California, llame a Lane haciéndose pasar por el director de Junk. Esto ejemplifica la facilidad con la que se puede construir una noticia falsa.

El propio gobierno estadounidense y el de Kuwait lo demuestran durante la Guerra del Golfo (1990-1991). Con el objetivo de que la población apoye la intervención en el conflicto, las cámaras recogen la terrible historia de la enfermera Nijirah-al Sabah. La joven afirma entre lágrimas que presenció cómo los soldados iraquíes entraron en un 
hospital y desenchufaron varias incubadoras dejando morir a los 312 bebés prematuros que estaban dentro. Añadió incluso que "los habían arrojado al suelo. La noticia dio la vuelta al mundo" (Pizarroso, 2008, p. 9). Después, se descubrió que todo era falso y que Nijirah era la hija del embajador de Kuwait en Estados Unidos.

Al igual que Nijirah, Glass también aparenta sentir temor y pinta a su enemigo, Lane, como malvado. Sin embargo, bajo esa fachada esconde una gran astucia que le permite idear todas estas maniobras. Tratará de poner a toda la plantilla y a su ex director en contra de Lane.

Stephen Glass.- Es vengativo, por eso me ha quitado de en medio. Me ha castigado por la lealtad que te profeso (al anterior director). Yo siento miedo de lo que pueda llegar a hacer.

El caso de Glass nos obliga a plantearnos hasta qué punto la urgencia por producir información y la exigencia de que ésta sea impactante, influye negativamente en los periodistas. Como él mismo reconoce:

Stephen Glass.- El periodismo es un trabajo muy duro. Todos estamos bajo presión y nos sacrificamos por sacar el número a tiempo.

La "infracarga” y la presión propician el sensacionalismo y la invención de hechos. Glass no es una excepción. Valbuena recoge otros casos célebres como el de la Premio Pulitzer de 1981 Janet Cooke, el de la sustituta de Cooke al descalificar a ésta, Teresa Carpenter, y el de Michael Daly (Valbuena, 1997, p. 86).

La necesidad de ser original para sorprender al público y que sigan el programa de radio/televisión o compren el ejemplar impreso ha influido en la aparición de un nuevo género: el infoentretenimiento.

Sorrentino atribuye su aparición a la mercantilización de la información, ya que cada vez más, se tratan temas sensacionalistas, relegando a un segundo plano las noticias políticas o duras (Ortells, 2009, pp. 341-353).

Amy.- El análisis político ya no es lo más importante. Ahora quieren color, quieren matices. Humor.

Caitlin.- Pero Amy, tu estilo no divierte.

Chuck Lane.- Nos entregó ficción tras ficción y nosotros lo publicamos. Sólo porque nos parecía divertido.

El concepto de infoentretenimiento se caracteriza por desdibujar los límites entre lo que se consideraba puramente informativo y el entretenimiento. Se aplica, sobre todo, a la televisión pero varios de los artículos de Glass de los que se habla en la película cumplen algunas de las características principales del género. Entre ellas destacan la espectacularización o el tener como protagonistas a gente anónima (VV.AA., 2009). 


\subsection{Buenas noches y buena suerte}

Esta película de 2005 dirigida por George Clooney retrata a un periodista real: Edward Murrow. Se convierte en un profesional muy valorado por su cobertura de la Segunda Guerra Mundial para la radio. Después, comienza su carrera en la televisión (CBS) y desde el principio concibe su trabajo como una forma de denunciar las injusticias: segregación, explotación de trabajadores inmigrantes, racismo... Buenas noches y buena suerte es la frase con la que se despide de la audiencia en su programa documental See it Now ("Véalo ahora").

Entre finales de los 40 y principios de los 50, el senador por el Estado de Wisconsin Joseph McCarthy inicia una cruzada contra el comunismo. Acusa a distintas personas, desde intelectuales a miembros de la Administración o del ejército, de apoyar o haber apoyado el comunismo e ir, por tanto, en contra de los principios norteamericanos. En 1953 McCarthy se convierte en el presidente de la Subcomisión Permanente de Investigaciones del Senado. Decide investigar a funcionarios gubernamentales y a las Fuerzas Armadas. En 1954 se presenta una moción de censura contra él.

Este período, que va de 1953 a 1954, es el que refleja el filme. Murrow se fija en el caso de Milo Radulovich y le dedica un programa. Se trata de un teniente irlandés al que expulsan de las Fuerzas Aéreas porque supuestamente su padre ha leído un diario serbio de línea comunista. Durante el juicio, los cargos contra Radulovich se presentan en un sobre cerrado y, si quiere conservar su puesto, debe acusar a su padre y su hermana. Poco después, dedica otra edición de See it Now a las actividades y los métodos que emplea el senador McCarthy.

Murrow y el editor de See it Now, Fred Friendly, son periodistas punitivos y participantes: creen que una de las misiones del periodismo es luchar contra las injusticias. Se arriesgan a perder a sus anunciantes, a la oposición de sus superiores y a las represalias que pueden derivar de cuestionar la labor de McCarthy porque consideran que su deber es sacar a la luz los excesos que está cometiendo. Son misioneros: quieren abrir los ojos a la audiencia.

Miembro de la directiva.- ¿Sabes en qué posición nos deja esto?

Fred.- Estamos en esto juntos el senador quiere...

Miembro de la directiva.- Ahórrame el discurso ese de que vamos en el mismo barco. Por favor, no me insultes. Tengo que volver con el señor Paley (el director de la CBS) y con Alcoa, que patrocina tu show y que resulta que tiene contactos militares. Ahora tengo que decirle que las pasarán canutas porque has tenido una bronca con Joe McCarthy. Ve a por Joe Kennedy, te pagaremos por ello. Tengo una gran historia sobre Hoover. ¿Sabes cuántos Person to Person tendrás que hacer para compensarnos por esto?

Murrow.- Judy y su hija Liza la semana que viene.

Miembro de la directiva.- No, entrevistarás a Rin Tin Tin. Hablaré con el Sr. Paley. Alcoa no pagará los anuncios y nosotros tampoco. Pero nadie te detendrá.

Murrow.- ¿Cuánto son los anuncios?

Miembro de la directiva.- 3.000 dólares. 
Murrow.- Fred y yo pagaremos a medias.

Aquí puede verse el choque entre el periodista de revelación, al que le preocupa la noticia, y el mánager, más próximo a un hombre de negocios que se interesa por la buena marcha de la empresa. Les explica que para la cadena es perjudicial que traten el tema de McCarthy porque se quedan sin uno de sus anunciantes: aceros Alcoa. Este es el segundo filtro dentro de la Teoría de la Propaganda de Herman y Chomsky: la publicidad. "Para hacer negocios se necesita el beneplácito de la publicidad... El poder de los anunciantes sobre la programación televisiva se debe sencillamente a que son ellos los que compran y pagan los programas" (Herman y Chomsky, 2001, pp. 43-46).

Para sacar adelante esta edición de See it Now, el propio conductor y su editor han de poner de su bolsillo el dinero que paga aceros Alcoa normalmente por publicitarse.

Murrow ofrece al senador McCarthy la posibilidad de participar en su espacio para puntualizar algunas de las cosas que han dicho sobre él. El político aprovecha la ocasión para acusarle de haber apoyado la propaganda de las causas comunistas. La semana siguiente, Murrow se defiende de las acusaciones con argumentos. No se altera pero es contundente.

Poco después, el Senado comienza a investigar a McCarthy y el ejército le acusa de presionar para lograr un trato preferente para David G. Schine, principal consultor de la Subcomisión Permanente de Investigaciones del Senado. Pese a ello, el director de la CBS, el Señor Paley, le pide a Murrow y Fred que vayan a su despacho.

Sr. Paley.- El problema no es sólo que hayáis perdido a vuestro patrocinador. Con Alcoa, See it Now sigue perdiendo dinero.

Fred.- Ellos pagan 50.000 y lo hacemos por menos de 50.000.

Sr. Paley.- Fred no sabes lo que dices.

Murrow.- Encontraremos otro patrocinador, podemos encontrar...

Sr. Paley.- "64.000 dólares Question" (La pregunta de los 64.000 dólares) recauda 80.000 en patrocinadores y cuesta un tercio de lo que hacéis. La programación del martes es la número uno. La gente quiere divertirse. No quiere una lección de civismo (...).

Sr. Paley.- Deberías enseñar periodismo. Tú y el señor Friendly (...) Tu programa pasa de media a una hora. No será semanal y no será los martes por la noche... Los domingos por la tarde. Cinco episodios.

Murrow.- ¿Por qué no me despides, Bill?

Sr. Paley.- Ninguno de los dos quiere eso.

El director de la CBS es un mánager, que se preocupa por la rentabilidad de su empresa. Sus consideraciones son muy diferentes a las de Fred o Murrow. Él no piensa en el periodismo como el cuarto poder, como una forma de garantizar la libertad o vigilar los desmanes de otros poderes. Sólo le interesa obtener beneficios. Es el primero de los filtros de la Teoría de la Propaganda. Los anunciantes (segundo filtro) son la base de la rentabilidad de una cadena. Como explica el Sr. Paley, ellos invierten 
en las franjas horarias con más audiencia y prefieren los espacios que simplemente entretienen.

"Para una cadena de televisión, la pérdida o ganancia de un punto de audiencia en el índice Nielsen se traduce en una alteración en los beneficios derivados de la publicidad que va de los ochenta a los cien millones de dólares (...)"(Herman y Chomsky, 2001, p. 46).

De ahí, la necesidad de desplazar See it Now de la noche del martes y sustituirlo por un rentable y nada problemático programa de entretenimiento.

En octubre de 1958, Murrow recibe un premio de periodismo por primar el derecho de la audiencia a conocer la verdad a su propia comodidad y seguridad. En el discurso que pronuncia, habla de la oposición de los dos filtros (la cadena, a través de sus accionistas, y los anunciantes) al periodismo de análisis frente a su defensa del que simplemente distrae:

Murrow: De vez en cuando recalcamos la importancia de las ideas y la información... Soñemos hasta decir que un domingo por la noche en una franja ocupada por Ed Sullivan, se dedica al estado del análisis de la educación americana. Y una semana o dos después, la franja de Steve Allen se dedica a un estudio minucioso de la política en Oriente Medio. ¿Se vería dañada la imagen de sus patrocinadores? ¿Se alzarían los accionistas enojados y quejándose?

Reivindica la función educadora de la televisión. Es consciente de su influencia a la hora de transmitir valores e ideas, de su papel como creadora de realidad e inductora de comportamientos. El problema es que los dueños de esas corporaciones de las que habla, también conocen el poder de los medios y se sirven de ellos para educar en los valores que interesan a nuestro sistema de consumo.

Murrow: ¿Pasaría alguna otra cosa a parte de que unos millones de personas habrían recibido un poco de educación sobre temas que podrían determinar el futuro del pais, y, por tanto, el futuro de las corporaciones? A los que dicen que la gente no lo vería, que son demasiado indulgentes, indiferentes e insensibles, les respondería que en opinión de este reportero hay pruebas suficientes contra esta afirmación. Pero aunque tengan razón, ¿qué pueden perder? Porque si tienen razón, y este aparato sólo sirve para entretener y aislar entonces el tubo empezará a parpadear y pronto veremos que toda la lucha se ha perdido. Este aparato puede enseñar. Puede iluminar y sí, puede incluso inspirar. Pero sólo puede hacerlo si los humanos estamos dispuestos a usarlo con este fin.

Es un periodista comprometido no con una causa concreta sino con su audiencia. Desea informar al público de la auténtica realidad, más allá de las apariencias que los poderosos se esfuerzan por construir. Desde el punto de vista psicológico es dinámico como estilo de comportamiento secundario. Reacciona de forma rápida ante las múltiples cuestiones que surgen en su trabajo diario y sabe guiar a su equipo. Como estilo primario es intuitivo. Es consciente de que está viviendo los comienzos del medio y de que esas bases sentarán el futuro: 
Murrow: Nuestra historia será la que inventemos. Y si hay historiadores dentro de 50 o 100 años y se conservan los cinescopios de una semana de las tres cadenas, encontrarían grabadas en blanco y negro y en color, pruebas de decadencia, escapismo y aislamiento de la realidad del mundo que nos rodea.

\subsection{Frost contra Nixon}

Dirigida por Ron Howard (Frost-Nixon 2008) Frost contra Nixon refleja el periplo del presentador y periodista David Frost desde que se propone entrevistar al ex presidente Richard Nixon hasta que termina su serie de cuatro entrevistas con él.

Nixon es el primer presidente en la historia de EEUU que dimite de su cargo debido al escándalo Watergate. El 17 de junio de 1972, cinco hombres entraron en la sede del Comité Nacional Demócrata para robar documentos e intervenir las comunicaciones. En enero de 1973 se juzga a estos cinco hombres y a dos más por conspiración, robo y violación de la ley de intervención de las comunicaciones.

Las investigaciones de dos periodistas del Washington Post (Bernstein y Woodward) y la del Senado, revelan que Nixon está relacionado con la operación y que graba todas sus conversaciones. Se niega a entregar las cintas hasta que en julio de 1974 el Tribunal Supremo le obliga a hacerlo. Se inicia un proceso de impeachment (procesamiento de un alto cargo público) contra él y finalmente dimite el 8 de agosto.

Frost hace reportajes sobre temas de entretenimiento. Desde Australia, sigue por televisión la salida de Nixon de la Casa Blanca y se le ocurre una idea: entrevistarlo. Gracias a un indulto del presidente que le sustituye, Ford, Nixon no tiene que ir a juicio. Se traslada a California y pasa sus días en una villa al lado del mar. Algunos consideran que una entrevista es la forma de que dé la cara por lo que hizo. Sin embargo, lo que motiva a Frost es la cantidad de telespectadores a los que puede atraer.

Jim Reston es un profesor de universidad e investigador que ha escrito varios libros sobre la corrupción y los abusos de poder de Nixon. Le plantea a Frost una pregunta sencilla sobre lo primero que un periodista debe pensar antes de hacer una entrevista:

Jim.- ¿Qué esperas conseguir con esta entrevista?

Frost.- ¿Qué quiero conseguir? Jim, a ver, he reservado 12 dias de grabación. Eso son casi 30 horas con el político más enigmático y polémico de nuestro tiempo. ¿Eso no te basta?

Jim.- Bueno, no para mí. Renunciaría a un año de mi vida, dejaría a mi familia para trabajar en algo que significa más para mí de lo que imaginas. Y hacer algo así sin conseguir lo que yo quiero sería impensable.

Frost.- ¿Y qué es lo que quieres conseguir?

Jim.- Me gustaría darle a Richard Nixon el juicio que nunca tuvo.

Frost.- Está claro que le haremos preguntas difíciles. 
Jim.- Preguntas difíciles... Murieron 21.000 americanos y un millón de indochinos durante su mandato. Sólo se libró de la cárcel gracias a Ford.

Ni siquiera se ha documentado o ha pensado qué va a preguntarle. Ve el periodismo como un instrumento con el que alcanzar fama y los privilegios que derivan de ella (desde tener mesa en el mejor restaurante de la ciudad a atraer a las mujeres). Es un periodista grato al que le interesa gustar a la audiencia. Se siente complacido cuando la gente le pide autógrafos. Él mismo explica que las conversaciones con Nixon son la forma de volver a ser famoso en los Estados Unidos.

Los reporteros y conductores de programas serios como Mike Wallace, del programa documental 60 Minutos (CBS), se ríen de él. No comprenden por qué un reportero especializado en entretener está interesado en entrevistar al único presidente de los Estados Unidos que ha dimitido. Wallace prepara, incluso, un especial sobre el proyecto de Frost, que se siente humillado. Los asesores de Nixon también lo infravaloran: "Frost ni se acerca a su clase intelectual", "será un masaje continuo".

Sin embargo, pese a estar interesado únicamente en la fama y no ver en el periodismo un instrumento de análisis social o una forma de luchar contra las injusticias, es un hombre creativo. Primero, tiene la idea de poner a Nixon frente a las cámaras. Busca una cadena de televisión norteamericana que compre su producto y lo emita, pero no lo consigue. Entonces, se le ocurre una forma nueva para llegar hasta su objetivo. Tiene un estilo intuitivo.

Frost.- ¿Dónde está tu espíritu aventurero? La idea es pagar nosotros el programa y distribuirlo nosotros al margen de las cadenas. Imagínatelo, seríamos nuestra propia cadena. ¿Cómo suena eso?

Interlocutor.- Eso nunca se ha hecho.

Frost.- Es algo histórico.

También es dinámico. Toma decisiones de forma rápida, actúa.

Frost.- Me gusta mantenerme ocupado... Me parece más interesante que estarme quieto.

No cede a las presiones ni a las amenazas de los colaboradores de Nixon para que evite todo tema espinoso excepto el Watergate. Sin embargo, no invierte mucho tiempo preparando sus preguntas e informándose. Son su productor, el investigador Jim Reston y Bob Zelnick (corresponsal de la radio pública durante 10 años) los que preparan las entrevistas.

El 23 de marzo de 1977 comienzan a grabar el primer bloque, dedicado a política interior. Nixon domina la situación. Es un especialista en la estrategia del cambio de tema. Parece que va a responder a la pregunta que le hace $y$, de repente, comienza a divagar. También utiliza la sorpresa tratando de descolocarle y establece contactos informales para ver hasta qué punto será duro con el asunto Watergate. 
Frost comete un error gravísimo: por un lado, no tiene sentido del tiempo, y por el otro no sabe cortar a Nixon y enfrentarle a la cuestión que realmente quiere que responda. Pasan los días, cubren los tres primeros bloques, y la situación se repite. Los asesores de David critican sus dotes de entrevistador y recibe una llamada desde Australia para informarle de que han cancelado su programa. Poco después, Nixon le llama para decirle que va a luchar y a vencer durante el último bloque: el que está dedicado al Watergate.

Estas circunstancias, lejos de hundirle, le motivan para preparar su siguiente y última intervención. Manda a Jim a que investigue la reunión de Nixon con Charles Colson. Ahora es Frost el que sorprende a Nixon utilizando una información bomba.

Frost.- Bien, siempre ha afirmado que no supo lo del allanamiento hasta el 23 de junio.

Nixon.- (Asiente).

Frost.- Pero esta transcripción de una cinta hecha tres dias antes claramente demuestra que era falso. En ella le dice a Colson: toda esta investigación se queda ahi, a menos que uno de los siete empiece a hablar. Ese es el problema.

Consigue que Nixon se enfrente a lo que la opinión pública desea: su actuación en el caso Watergate. Incluso que reconozca que cometió errores e hizo algo ilegal.

Es importante remarcar que Frost no cambia su actitud hacia Nixon porque crea que es justo que el pueblo americano tenga una respuesta o porque quiera luchar contra una injusticia o el exceso del poder ejecutivo. Simplemente, lo hace porque es necesario para su popularidad y para obtener beneficios. Por tanto, le mueve el interés personal. De hecho, las entrevistas consiguieron la mayor audiencia de un espacio de estas características y salió en la portada del Time y el Newsweek. Hasta los periodistas especializados en política le felicitaron.

\section{CONCLUSIONES}

Las cinco películas analizadas nos ofrecen fundamentalmente tres imágenes: la del periodista de investigación/periodista comprometido, la del mánager o gerente y la del periodista grato.

\begin{tabular}{|l|l|l|l|l|l|l|}
\hline Película & Personajes & \multicolumn{1}{|c|}{ Imágenes } & Características & \multicolumn{1}{|c|}{$\begin{array}{c}\text { Estilo } \\
\text { comp. } \\
\text { protago. }\end{array}$} & $\begin{array}{c}\text { Relación con los } \\
\text { responsables del medio }\end{array}$ & $\begin{array}{l}\text { Relación } \\
\text { con otros } \\
\text { poderes }\end{array}$ \\
\hline El Dilema & $\begin{array}{l}\text { Lowell } \\
\text { Bergman }\end{array}$ & $\begin{array}{l}\text { Periodista de } \\
\text { investigación, } \\
\text { compometido, } \\
\text { divulgador, } \\
\text { misionero } \\
\text { Meriodista de } \\
\text { Mike Wallace } \\
\text { comprometido } \\
\text { aunque hay un }\end{array}$ & $\begin{array}{l}\text { Valiente, quiere } \\
\text { revelar verdades } \\
\text { ocultas }\end{array}$ & $\begin{array}{l}\text { Intuitivo- } \\
\text { dinámico } \\
\text { Valiente, quiere } \\
\text { revelar verdades } \\
\text { ocultas }\end{array}$ & $\begin{array}{l}\text { Negativa: le presionan } \\
\text { para que no emita la } \\
\text { información }\end{array}$ & $\begin{array}{l}\text { Judicial: } \\
\text { positiva. } \\
\text { Económico: } \\
\text { negativa. }\end{array}$ \\
\hline
\end{tabular}




\begin{tabular}{|c|c|c|c|c|c|c|}
\hline & $\begin{array}{l}\text { Mujer de la } \\
\text { Directiva }\end{array}$ & $\begin{array}{l}\text { momento en que } \\
\text { duda) } \\
\text { Mánager }\end{array}$ & $\begin{array}{l}\text { Interesada en los } \\
\text { beneficios }\end{array}$ & & & \\
\hline $\begin{array}{l}\text { Verónica } \\
\text { Guerin }\end{array}$ & $\begin{array}{l}\text { Verónica } \\
\text { Guerin }\end{array}$ & $\begin{array}{l}\text { Periodista de } \\
\text { investigación, } \\
\text { comprometida, } \\
\text { misionera, } \\
\text { punitiva, } \\
\text { abogada, } \\
\text { adversaria }\end{array}$ & $\begin{array}{l}\text { Valiente, quiere } \\
\text { revelar verdades } \\
\text { ocultas }\end{array}$ & $\begin{array}{l}\text { Intuitivo- } \\
\text { dinámico }\end{array}$ & Positiva: la apoyan & $\begin{array}{l}\text { Ejecutivo: } \\
\text { positiva. } \\
\text { Fuerzas de } \\
\text { seguridad } \\
\text { (policía): } \\
\text { positiva. }\end{array}$ \\
\hline $\begin{array}{l}\text { El precio } \\
\text { de la } \\
\text { verdad }\end{array}$ & Stephen Glass & Periodista grato & $\begin{array}{l}\text { Vanidoso, } \\
\text { manipulador, } \\
\text { busca } \\
\text { reconocimiento y } \\
\text { poder }\end{array}$ & $\begin{array}{l}\text { Intuitivo- } \\
\text { dinámico }\end{array}$ & $\begin{array}{l}\text { Positiva: hasta que se } \\
\text { descubren sus mentiras }\end{array}$ & $\begin{array}{l}\text { No se } \\
\text { muestra. }\end{array}$ \\
\hline $\begin{array}{c}\text { Buenas } \\
\text { noches y } \\
\text { buena } \\
\text { suerte }\end{array}$ & $\begin{array}{l}\text { Eduard } \\
\text { Murrow } \\
\text { Fred Friendly } \\
\text { Bill Paley } \\
\text { Miembro de } \\
\text { la directiva }\end{array}$ & $\begin{array}{l}\text { Periodista de } \\
\text { investigación, } \\
\text { comprometido, } \\
\text { misionero, } \\
\text { participante, } \\
\text { punitivo. } \\
\text { Per. } \\
\text { comprometido, } \\
\text { misionero, } \\
\text { participante. } \\
\text { Mánager } \\
\text { Mánager }\end{array}$ & $\begin{array}{l}\text { Valiente, quiere } \\
\text { revelar verdades } \\
\text { ocultas } \\
\text { Valiente, quiere } \\
\text { revelar verdades } \\
\text { ocultas } \\
\text { Interés por los } \\
\text { beneficios } \\
\text { Interés por los } \\
\text { beneficios }\end{array}$ & $\begin{array}{l}\text { Intuitivo- } \\
\text { dinámico }\end{array}$ & $\begin{array}{l}\text { Negativa: les presionan } \\
\text { y recortan su tiempo de } \\
\text { emisión }\end{array}$ & $\begin{array}{l}\text { Ejecutivo: } \\
\text { negativa. } \\
\text { Fuerzas de } \\
\text { seguridad } \\
\text { (militar): } \\
\text { negativa. }\end{array}$ \\
\hline $\begin{array}{c}\text { El } \\
\text { desafio: } \\
\text { Frost } \\
\text { contra } \\
\text { Nixon }\end{array}$ & David Frost & Periodista grato & $\begin{array}{l}\text { Fama, } \\
\text { reconocimiento }\end{array}$ & $\begin{array}{l}\text { Intuitivo- } \\
\text { dinámico }\end{array}$ & $\begin{array}{l}\text { Negativa: acaban por } \\
\text { cancelar su programa }\end{array}$ & $\begin{array}{l}\text { Ejecutivo: } \\
\text { negativa. }\end{array}$ \\
\hline
\end{tabular}

Tabla 2: Imágenes, características, relación con el MCM y con otros poderes de los periodistas que aparecen en la muestra analizada. Fuente: elaboración propia.

Los periodistas comprometidos (Lowell, Guerin, Murrow, Friendly y Wallace), quieren mostrar qué hay debajo de la fachada creada por los poderosos o los corruptos. Consideran que se deben a su audiencia y ven en su profesión un instrumento con el que cambiar las cosas. Los mánager se interesan por los beneficios económicos y buscan servir a los anunciantes y accionistas que se los proporcionan. Los gratos quieren agradar a la audiencia.

El público es para Glass y Frost la forma de obtener fama y reconocimiento. Glass miente y engaña al inventar fuentes y hechos poniendo en peligro la credibilidad del 
medio para el que trabaja. El caso de Frost es diferente. Consigue algo positivo, que Nixon dé la cara, aunque le mueva el afán de notoriedad.

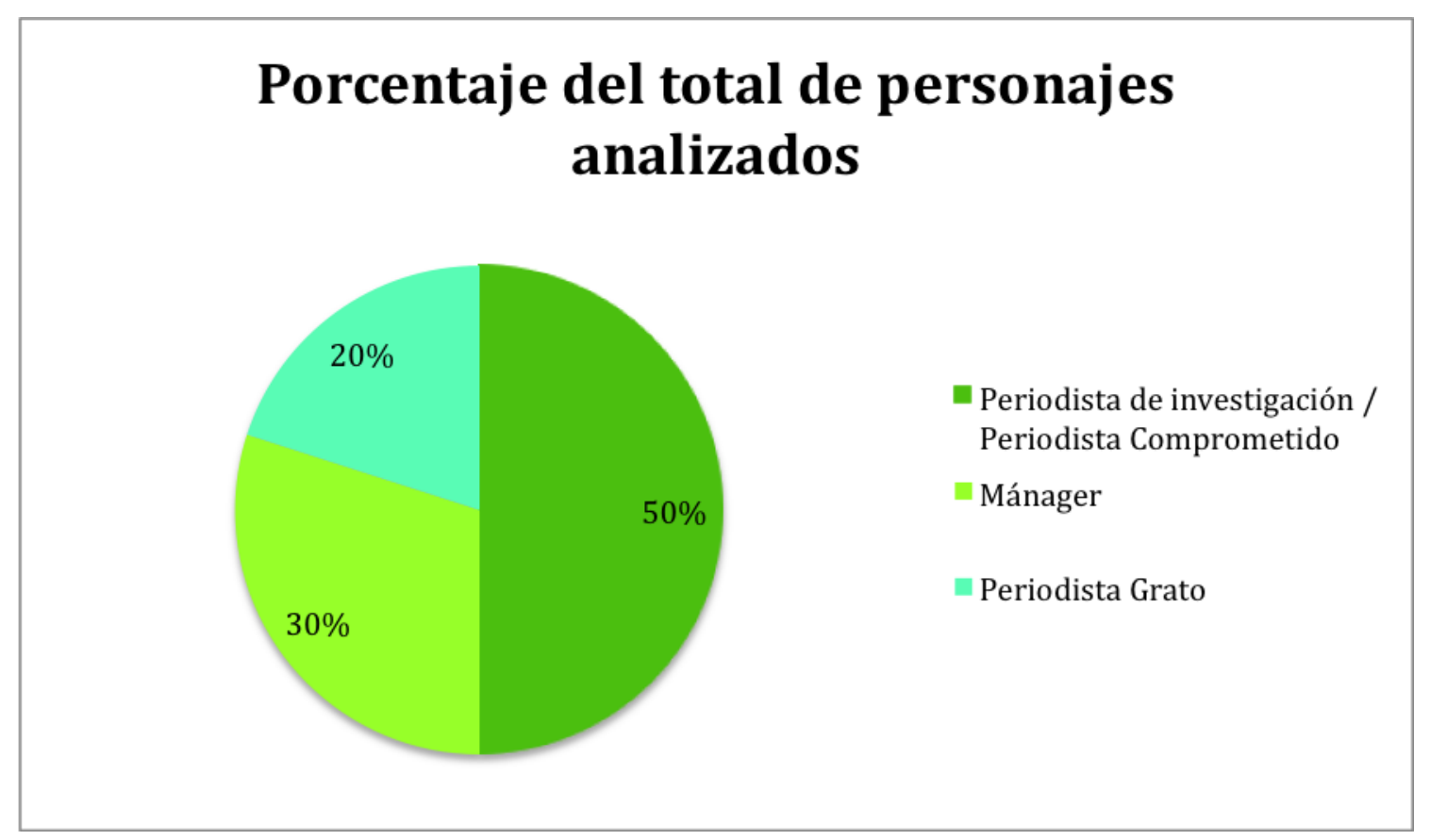

Gráfico 2: Imágenes a las que se ajustan el total de los 10 personajes analizados (en \%). Fuente: elaboración propia.

Tres de los cinco protagonistas (Bergman, Murrow y Guerin) son periodistas de investigación. Las consecuencias de su labor son muy positivas desde la perspectiva social. Gracias al trabajo de Bergman millones de personas descubren que determinadas tabacaleras manipulan la nicotina. Murrow saca a la luz los excesos de poder de McCarthy. Verónica Guerin desenmascara a John Gilligan, uno de los principales narcotraficantes de Irlanda. Sin embargo, en dos de los tres casos, su trabajo se ve amenazado por los directivos de su propio medio. Es la clásica oposición entre el "auténtico periodista" y el hombre de negocios. Guerin no sufre las presiones de sus superiores, pero es asesinada por uno de los colaboradores de Gilligan.

Los cinco personajes principales muestran un estilo de comportamiento intuitivodinámico.

Sí están presentes las relaciones con otros poderes. Se reflejan, sobre todo, los vínculos con el ejecutivo (presente en tres de los cinco filmes). La visión es negativa en dos de los tres casos (Buenas noches y buena suerte y Nixon contra Frost). También aparecen las fuerzas de seguridad (policía y militares), el poder judicial y el económico. Verónica Guerin muestra los beneficios que pueden derivar de la colaboración (con el ejecutivo y las fuerzas de seguridad). 
Esta propuesta pretende servir al análisis de otros filmes sobre periodistas. La base de datos del IJPC y la de películas calificadas del Ministerio de Cultura de España pueden ser muy útiles para la selección de títulos. Una vez hecho esto, consideramos que la metodología y las principales líneas propuestas (imágenes, estilo de comportamiento, relación con el medio y con otros poderes) permiten determinar de forma completa la representación que el cine hace del profesional de los medios.

Sería muy interesante profundizar en: a) la investigación sobre los estilos de comportamiento y b) la relación con otros poderes. El objetivo es descubrir si hay imágenes a las que les suele acompañar un estilo concreto y si los principales poderes que aparecen y su representación varían dependiendo de distintos factores (momento histórico en que se ha realizado el filme, época en que se desarrolla la narración, tipo de periodista al que se representa, etc...).

\section{REFERENCIAS}

Barris, Alex (1976). Stop the Presses! The Newspaperman in American Films. London: Thomas Yoseloff.

Bowman, William, Salawski, Edward, y Johnstone, John (1972). "The Professional Values of American Newsman". En Public Opinion Quarterly, 36 (4), pp. 522-540.

Caminos, José María (1997). "Periodismo de filtración, periodismo de investigación". En Zer, n², mayo, http://www.ehu.es/zer/zer2/9artcami.html

Chomsky, Noam y Herman, Edward (2001). Los guardianes de la libertad. Barcelona: Crítica.

De Sola Pool, Ithiel y Shulman, Irwin, (1964). “Newsmen's fantasies, Audiences and Newswriting". En Dexter, A. y White, H.D. (compiladores) People, Society and Mass Communication. New York: The Free Press of Glencoe, pp. 141-158.

Janowitz, Morris (1960). The Profesional Soldier. Glencoe: Free Press.

Jung, Carl Gustav (1971). Tipos psicológicos I y II. Barcelona: Edhasa.

Laviana, Juan Carlos (1996). Los chicos de la prensa. Madrid: Nickel Odeón.

Osorio, Olga (2009). La imagen de la periodista profesional en el cine de ficción de 1990 a 1999. La Coruña: Universidad de La Coruña. Tesis doctoral defendida el 9 de octubre de 2009.

Ortells, Sara (2009). "La mercantilización de la información: la nueva era informativa en televisión". En Revista Latina de Comunicación Social. Tenerife: Universidad de La Laguna, $n^{\circ}$ 64, 2009, pp. 341-353,

http://www.revistalatinacs.org/09/art/28_827_46_ULEPICC_07/Sara_Ortells.html 
Pizarroso, Alejandro (2008). "Justificando la guerra. Manipulación de la opinión pública en los conflictos más recientes". En Comunicación: revista Internacional de Comunicación Audiovisual, Publicidad y Estudios Culturales, vol. 1, n6, 2008, pp. 3-19.

Saltzman, Joseph (2002a). Introduction to the Image of the Journalist in Popular Culture. En IJPC, Ann Annenberg: University of South California (USC).

http://www.ijpc.org/uploads/files/ijpcintro.pdf

Saltzman, Joseph (2002b). Frank Capra and the Image of the Journalist in American Film. Los Ángeles: The Norman Lear Center, University of South California (USC).

Segovia, Ana Isabel (2004). "Repercusiones y cambios de las leyes de propiedad de medios de comunicación. El caso de Clear Channel Communications". En ZER, $\mathrm{n}^{\mathrm{o}} 16$, mayo, 2004, pp. 57-70.

Tunstall, Jeremy (1970). The Westminster Lobby Correspondents: A Sociological Study of National Journalism. Londres: Routledge \& Kegan Paul.

Valbuena, Felicísimo (1997). Teoría General de la Información. Madrid: Nóesis.

VV. AA. (2009). Telerrealidad. El mundo tras el cristal. Sevilla: Comunicación Social Ediciones y Publicaciones.

\section{Paula Requeijo Rey}

Doctora en Teoría de la Información por la Universidad Complutense de Madrid (UCM), trabaja como Personal Investigador Contratado en la Facultad de Ciencias de la Información de esta Universiad. Se licenció en Periodismo en junio de 2006 por la UCM y cursó el Máster de esta universidad y Radio Nacional de España. Tras trabajar como periodista en Radio Nacional entre 2007 y 2009, se incorporó al Departamento de Periodismo III, Facultad de Ciencias de la Información, UCM, dentro del programa investigador FPU (Formación del Profesorado Universitario) del Ministerio de Educación. Sus principales líneas de investigación se centran en el estudio de los medios de comunicación (especialmente la televisión y el cine), la comunicación interpersonal, la comunicación no verbal y la comunicación política. 